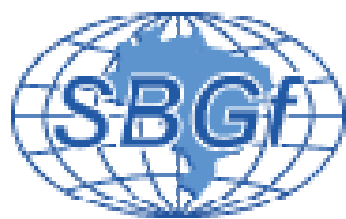

\title{
Interpretação de perfil de refração sísmica sobre o eixo da Cordilheira Mesoatlântica em $22^{\circ} \mathrm{N}$
}

\author{
Marisa Makler ${ }^{1}$ Marcia Maia ${ }^{2}$, Julie Perrot $^{2}$, and Sidney Mello ${ }^{3}$ \\ 1- Instituto de Física/Laboratório de Geologia Marinha LAGEMAR, Universidade federal Fluminense, RJ, Brasil. \\ 2- Centre National de la Recherche Sientifique UMR 6538, Université de la Bretagne Occidentale, Brest, France. \\ 3- Laboratório de Geologia Marinha LAGEMAR, Universidade federal Fluminense, RJ, Brasil.
}

Copyright 2006, SBGf - Sociedade Brasileira de Geofísica

Este texto foi preparado para a apresentação no II Simpósio de Geofísica da Sociedade Brasileira de Geofísica, Natal, 21-23 de setembro de 2006. Seu conteúdo foi revisado pela Comissão Tecno-científica do li SR-SBGf mas não necessariamente representa a opinião da SBGf ou de seus associados. E proibida a reprodução total ou parcial deste material para propósitos comerciais sem prévia autorização da SBG.

\section{Resumo}

O IFREMER, Instituto de Marinho de Pesquisas da França, por meio da Campanha COSTMAR - RV Meteor, adquiriu dados geofísicos, incluindo perfis sísmicos de alto ângulo, visando caracterizar a profundidade e a natureza da crosta oceânica em um alto do canto interno (inside corner high) localizado no eixo da Cordilheira Mesoatlântica ao sul da Zona de Fratura Kane.

Este trabalho interpreta os dados de sísmica de refração a partir da análise de velocidade das ondas $\mathrm{P}$, com $\mathrm{O}$ intuíto de reconhecer a estrutura interna da crosta oceânica. Com base nestes dados foi possível elaborar um modelo básico de camadas da crosta oceânica diferenciadas por suas densidades: camada 1 (sedimentos) - sem registro, camada 2 (basalto) - 2.740 $\mathrm{kg} / \mathrm{m}^{3}$, camada 3 (grabro) - $2.790 \mathrm{~kg} / \mathrm{m}^{3}$ e camada 4 (peridotitos serpentinizados) - $2.870 \mathrm{~kg} / \mathrm{m}^{3}$ camada 5 (manto) $-3.300 \mathrm{~kg} / \mathrm{m}^{3}$. Tais densidades serviram para compor um modelo gravimétrico, que está de acordo com o modelo geológico no qual se prevê um afinamento da camada basática e o afloramento de peridotitos serpentinizados em altos do canto interno de zonas de fratura.

\section{Introdução}

Vários trabalhos têm mostrado que a estrutura da crosta oceânica criada no eixo da cordilheira mesoceânica varia no tempo e no espaço, refletindo a variabilidade no processo de acresção crustal. O eixo da cordilheira é fragmentado e dividido em segmentos que são separados por descontinuidades transformantes ou nãotransformantes (e.g., Macdonald et al., 1991). A crosta oceânica é formada no centro de um segmento, enquanto as descontinuidades nas extremidades dos segmentos são locais de pouca produção magmática (e.g. Cannat et al., 1995). Deste modo, o centro de um segmento apresenta crosta oceânica mais espessa do que as suas extremidades, onde a mínima cobertura basáltica permite com que as rochas do manto cheguem a aflorar. Os afloramentos de maciços peridotíticos fortemente serpentinizados constituem marcantes altos no canto interno entre zonas trasnformante (Fig. 1). Evidências geológicas e geofísicas destes maciços são, por exemplo, reportadas em Cann et al. (1997) e Blackman et al. (1998). A figura 2 apresenta a variabilidade da topografia ao longo de segmentos da cordilheira com base em distintos espisódios magmátcos. Observe que o alto do canto interno (Figs. 1 e 2) é comumente associado a falhamentos de baixo ângulo, superfícies de descolamento e afloramento de serpentinitos.

O perfil aqui interpretado é transversal a um alto topográfico, que está localizado no canto interno da zona de fratura Kane em torno de $22^{\circ} \mathrm{N} / 46^{\circ} \mathrm{W}$ (Fig. 3). Ao longo deste perfil foram levantados dados geofísicos de sismica de refração (OBS e $\mathrm{OBH}$ ) e gravimetria que serviram para caracterizar a estrutura da oceânica subjacente e confirmar a natureza ultramáfica das rochas do alto topográfico.

Esse estudo aborda a variação da espessura crustal ao longo do eixo da cordilheira, na região do canto interno da zona transformante de Kane. Trata-se de uma contribuição sobre a estrutura de um maciço ultramáfico, proporcionando informações para melhor compreender os mecanismos de formação destes altos.

\section{Metodologia}

Para a inversão de sísmica de refração foram utlizados os OBH-68, OBH-69, OBH-70, OBH-71, OBH-72, OBH73 e $\mathrm{OBH}-74$. Modelos para inversão de dados e análise do tempo de propagação de ondas sísmicas, com base em Zelt and Smith (1992), foram utilizados de modo a obtermos um modelo de velocidade 2-D. Com base neste modelo determinamos a estrutura das interface sísmicas.

A figura 3 apresenta o referido modelo de velocidade elaborado a partir do software RAYINVR, associado ao perfil sísmico coletado (Fig.5). Considerando que 
podemos associar uma determinada densidade para as diferentes velocidades das ondas sísmicas, obtemos através do modelo de velocidades, um modelo análogo de densidades (Fig.6). Para esta modelagem foi utilizado o Gm-Sys, programa da Geosoft, capaz de computar o efeito gravimétrico causado por sucessivas camadas com diferentes densidades.

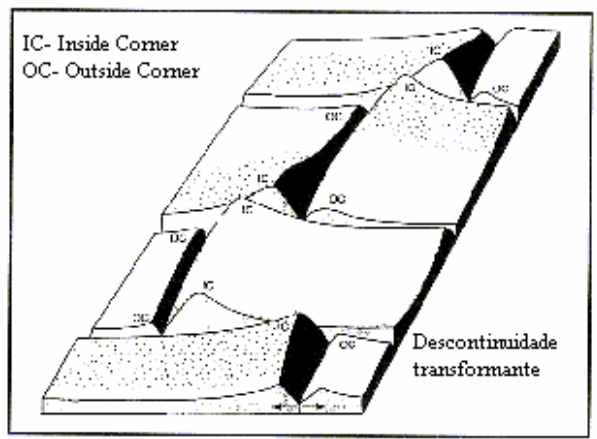

Figura 1 -Segmentação da Cordilheira, destaque para a zona de inside corner. Tucholke e Lin (1994).

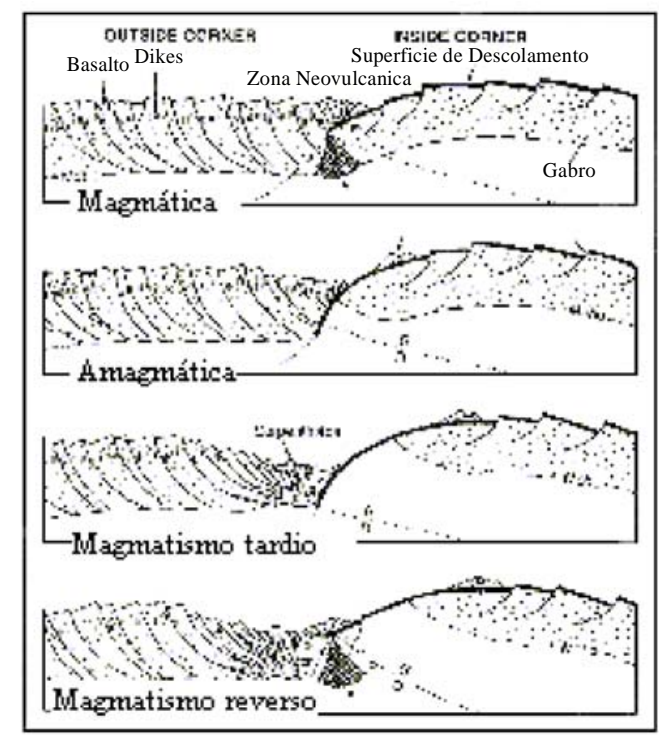

Figura 2 -Estrutura interna de um inside corner . Tucholke e Lin (1994).

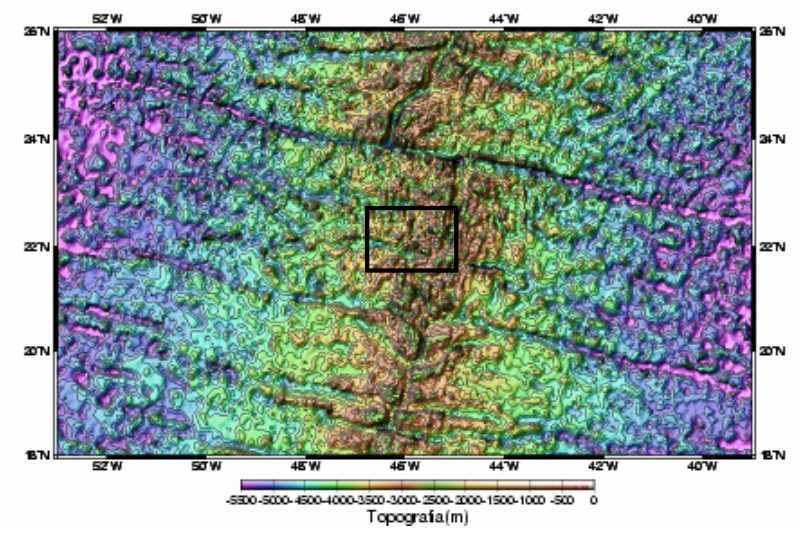

Figura 3 -Área de estudo.

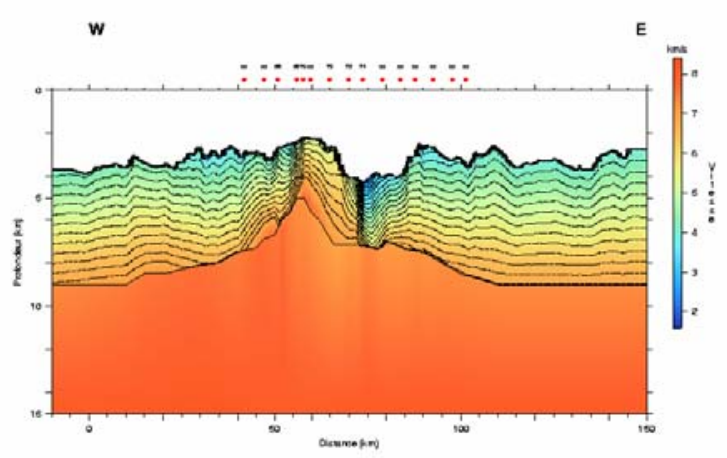

Figura 4 - Modelo de velocidades.

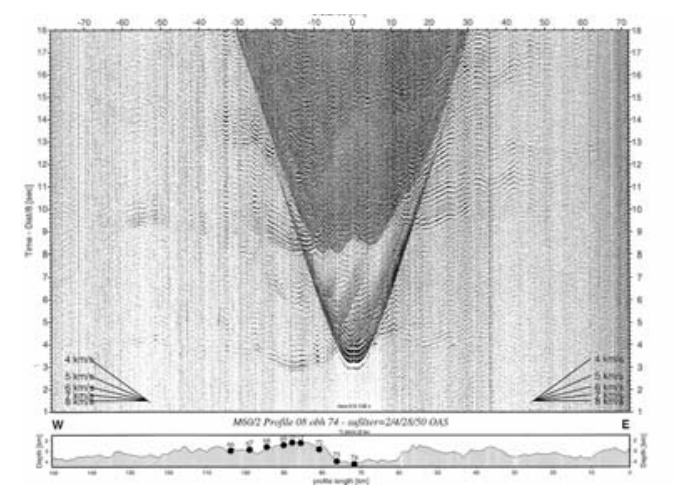

Figura 5 - Perfil sísmico.

\section{Resultados}

A inversão permitiu indentificar as camadas, com diferentes veleocidades: $7,00 \mathrm{Km} / \mathrm{s}$ ou mais para 0 manto; entre $6,90-6,00 \mathrm{Km} / \mathrm{s}$ para os peridotitos 
serpentinizados; $5,90-4,80 \mathrm{Km} / \mathrm{s}$ para o Gabro; 4,70 $4,00 \mathrm{Km} / \mathrm{s}$. A partir dessas velocidades foram estimadas densidades levando-se em conta a natureza da rocha a ser descrita em cada camada .

Esse modelo reflete um afinamento da crosta oceânica, especialmente a camada de basalto. Reflete ainda o soerguimento de rochas ultramáficas sepertinizadas, associadas ao alto do canto interno da zona de fratura. Considerando a ausência de dados no canto externo da zona de fratura, foi inferido no modelo uma sequência de crosta oceânica normal com camada de basalto de espessura $2 \mathrm{Km}$ e $3 \mathrm{Km}$ de gabro.

\section{Discussão e Conclusões}

A maioria dos trabalhos sobre a estrutura da crosta oceânica nas cordilheiras mesoceânicas tem sido realizados com base em dados gravimétricos. Estes dados permitem caracterizar e interpretar as variações de densidade em profundidade em termos de variações laterais de densidade dentro da crosta e do manto. Entretanto, a inversão de dados gravimétricos é sempre controversa, graças ao problema da multiplicidade soluções para uma mesma anomalia. Assim, a conjugação de dados gravimétricos e sísmicos (e.g., Tiberi et al., 2003) contribui na elaboração de modelos com menos incertezas, graças à independência da natureza destes dados geofísicos.

Esse estudo mostrou que o alto do canto interno da zona de fratura de Kane correspondente a um região de alta velocidade e densidade acentuada, caracterizando a natureza ultramáfica das rochas subjacentes. Isto corrobora o modelo geológico de variabilidade da segmentação da cordilheira descrito por Tucholke e Lin (1994).

\section{Agradecimentos}

Marisa Makler agradece à ANP pela bolsa de estudos; à parceria com a Universidade da Bretanha Ocidental, que deu viabilidade a este projeto; e ao Eduardo Mio, que colaborou na utilização do programa Gm-Sys.

\section{Referências}

Blackman, D.K., Cann, J.R., Janssen, B., Smith, D.K.1998. Origin of extensional core complexes: Evidence from the Mid-Atlantic Ridge at Atlantis Fracture Zone. J. Geophys. Res, Vol. 103, 21315-21333.

Cann, J.R., Blackman, D.K., Smith, D.K., McAllister, E., Janssen, B., Mello, S., Avgerinos, E., Pascoe, R., and Escartin, J. 1997. Corrugated slip surfaces formed at ridge-transform intersections on the Mid-Atlantic Ridge, Nature, 385: 329-332.

Cannat, M., Mével, C., Maia, M., Deplus, C., Durand, C., Gente, P., Agrinier, P., Belarouchi, A., Dubuisson, G., Humer, E., Reynolds, J., 1995. Thin crust, ultramafic exposures, and rugged faulting patterns at] the MidAtlantic Ridge $\left(22^{\circ}-24^{\circ} \mathrm{N}\right)$, Geology, 23: 49-52.

Madonald, K.C., Scheirer, D.S., and Carbotte, S.M. 1991. Mid-Atlantic Ridge: discontinuities, segments and giant cracks. Science, 253: 986-994.

Tibéri, C., M. Diament, J. Déverchère, C. Petit, V. Mikhailov, S. Tikhotsky, and U. Achauer. 2003. Deep structure of the Baikal rift zone revealed by joint inversion of gravity and seismology, J. Geophys. Res, Vol. 108, No. B310.1029/2002JB001880.

Tucholke, B. E. and Lin, J. 1994. Ageological model for the structure of segments in slow spreading ocean crust, J. Geophys. Res, Vol. 99, No. 11937-11958.

Zelt, C. A. and Smith, R. B., 1992. Seismic traveltime inversion for 2-D crustal velocity structure, Geophysical Journal International, 108, 16-34. 


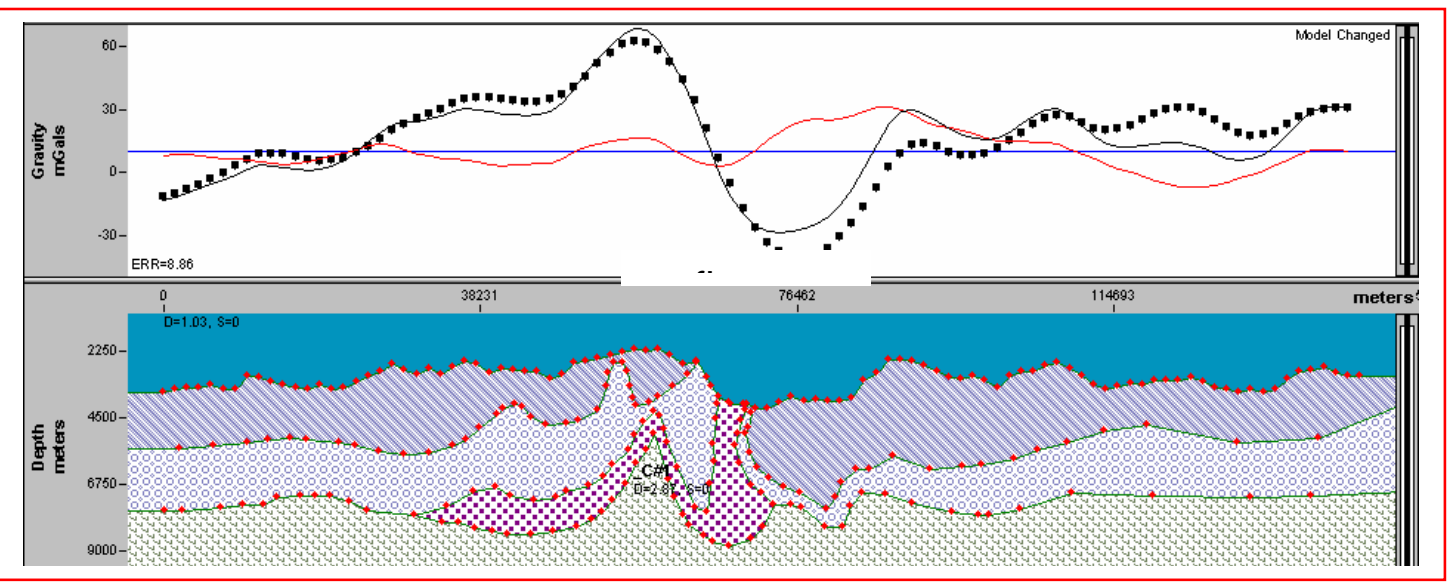

Figura 6 - Modelo de Camadas. 